DOI - https://doi.org/10.5965/2316796309182020052

\title{
Proposta de Modelo de Análise e Avaliação das Necessidades Humanas no Processo de Desenvolvimento de Produtos
}

\section{A Proposed Model for Analysing and Assessing Human Needs in the Product Development Process}

Gabriela Unger Unruh ${ }^{1}$ Osíris Canciglieri Junior ${ }^{2}$ 


\section{Resumo}

Desenvolver produtos, em essência, é sobre melhorar a vida das pessoas suprindo suas necessidades, assim como as necessidades organizacionais, sendo que humanos e organizações são sistemas complexos e dinâmicos, os quais necessitam de processos estruturados para promover boas relações e bons resultados aos negócios. Ainda existe falta de modelos claros que permitam a inserção, verificação e adequação das necessidades humanas no processo de desenvolvimento de produtos, portanto este artigo apresenta o modelo HUNE (HU - humano, NE - necessidades) para auxiliar na análise e avaliação das necessidades humanas, dos usuários, em processos de desenvolvimento de produtos e, sua aplicação em dois casos. Para isso foi desenvolvida uma pesquisa de natureza aplicada com abordagem qualitativa, por meio de revisão sistemática da literatura, construção do modelo HUNE e aplicação do modelo. O resultado foi um modelo que serve como orientação e auxílio na tomada de decisão nos momentos de análise do problema de projeto (pré-desenvolvimento) e avaliação do produto em desenvolvimento com relação às necessidades humanas. As aplicações permitiram verificar o processo de aplicação do modelo até a etapa de desenvolvimento de protótipo de baixa fidelidade, se mostrando coerente e indicando possíveis decisões de projeto que o levem a se adequar ao usuário. O modelo foi aplicado no desenvolvimento de dois casos experimentais alcançando resultados promissores, e principalmente, identificando novas oportunidades de aprofundamento e outras aplicações.

Palavras-chave: Design Centrado no Humano, Design Centrado no Usuário, Necessidades humanas, Desenvolvimento de Produto, Design de Produto.

\section{Abstract}

Developing products is about improving people's lives by meeting their needs, as well as organizational needs, with humans and organizations being complex and dynamic systems, which need structured processes to promote good relationships and good business results. There is still a lack of clear models that allow the insertion, verification and adequacy of human needs in the product development process, so this article presents the HUNE model (HU - human, NE - needs) to assist in the analysis and assessment of human needs, of users, in product development processes and its application in two cases. For that, a research of an applied nature was developed with a qualitative approach, through systematic literature review, construction of the HUNE model and application of the model. The result was a model that serves as guidance and aid in decision making when analysing the design problem (pre-development) and evaluating the product under development in relation to human needs. The applications allowed to verify the application process of the model until the stage of development of a low-fidelity prototype, showing itself to be coherent and indicating possible design decisions that lead it to adapt to the user. The model was applied in the development of two experimental cases, achieving promising results, and mainly, identifying new opportunities and other applications.

Key-words: Human-centred Design, User-centred Design, Human needs, Product Development, Product Design.

${ }^{1}$ Mestra - PUC-PR (gabriela.unruh@pucpr.br)

2 Doutor - PUC-PR (osiris.canciglieri@pucpr.br) 


\section{INTRODUÇÃO}

No processo de design é essencial considerar e envolver ao máximo as pessoas para quem o produto é desenvolvido (usuários) e suas interações com o produto em cada etapa de seu ciclo de vida, para gerar uma melhor configuração final do produto (VINCENT et al., 2014), melhor qualidade (KOLUS et al., 2018), melhor aceitabilidade do produto no mercado, coerência de contexto, eficiência de custos durante o processo de design até o pós-venda, e principalmente, o impacto e o valor significativo para a sociedade ( $\mathrm{CHOl}$ et al., 2018).

Aevoluçãoea criaçãocontínua de novastecnologiassãoconstantesantropológicas na prática social humana (BRÖDNER, 2013), novos produtos e serviços são criados com o objetivo de atender às necessidades sociais por meio da inovação (BENNETT e MCWHORTER, 2019). Estes fatos, no contexto atual, podem estar relacionados à inovação social (SI) com foco na melhoria da qualidade de vidas das pessoas. Embora, esta pesquisa não explore o tema inovação social, os autores acreditam que as organizações também possam ver seus produtos ou serviços como bens sociais ainda se beneficiarem do desempenho econômico e do desenvolvimento tecnológico, contribuindo na busca de soluções lucrativas, inovadoras e sustentáveis (BENNETT e MCWHORTER, 2019; BALYEIJUSA, 2019).

As Teorias das necessidades humanas (HNT) propõem explicações referentes aos sentimentos humanos e o que motiva as pessoas em suas ações e comportamentos em várias situações (MILYAVSKAYA e KOESTNER, 2011), e o campo das teorias de motivação está crescendo em interesse por causa de novas descobertas na área de estudo, relacionadas à multidisciplinaridade dessas teorias aplicadas em práticas de negócio e experiências cotidianas, que podem adicionar valor a pesquisas na busca da compreensão dos aspectos humanos em projetos (KISPAL-VITAL, 2016).

Para Smeenk et al. (2019) pesquisas focadas na formalização de metodologias orientadas às necessidades humanas estão expandindo e, portanto, a pesquisa reportada neste artigo apresenta a proposta do modelo HUNE (HU - humano; NE necessidades) e sua validação por meio de duas aplicações experimentais.

\section{PROCEDIMENTOS METODOLÓGICOS}

Esta pesquisa é considerada de natureza aplicada, porque deseja "conhecer com vistas de fazer algo de maneira mais eficiente ou eficaz" (GIL, 2010), sua abordagem é qualitativa porque, parte de epistemologias realistas, possui planejamento de ação concreto, existe conhecimento teórico relativo à pesquisa, pode ser relacionado a um pressuposto em cada fase do projeto e é empírica (FLICK, 2009). Seu objetivo científico é exploratório porque pretende tornar um problema mais explícito. Os procedimentos técnicos adotados foram a pesquisa bibliográfica e a aplicação em dois casos experimentais.

A pesquisa bibliográfica foi realizada de forma sistemática para identificar e analisar os modelos e métodos existentes no processo de desenvolvimento de produto orientado ao usuário ou humano, auxiliando e contribuindo na fundamentação, concepção e construção de um modelo. A partir da análise destes modelos e métodos, foi possível estruturar e propor um modelo e, posteriormente, ser aplicado em dois casos experimentais, verificando a sua coerência na análise e avaliação das necessidades humanas no processo de desenvolvimento de produtos. Estes procedimentos são apresentados nos próximos tópicos, na seguinte ordem: i) referencial teórico; ii) proposta do modelo HUNE; e iii) aplicação do modelo em dois casos experimentais.

\section{REFERENCIAL TEÓRICO}

Este item apresenta conceitos de design centrado no humano (DCH) e design centrado no usuário (DCU), e modelos, métodos e estruturas de desenvolvimento de produtos focados no humano/ usuário, encontrados na revisão sistemática da literatura, onde foi possível identificar e constatar lacunas e oportunidades relacionadas à inserção de aspectos das necessidades humanas no processo de desenvolvimento de produtos (PDP).

\subsection{Design centrado no humano (DCH) e no usuário (DCU)}

Basicamente, o design centrado no humano $(\mathrm{DCH})$ deve considerar ao máximo as necessidades humanas na formação dos requisitos de design. Neste contexto, Processo de desenvolvimento de produtos (PDP) aparece como uma forma sistêmica necessária para identificar o mercado, as necessidades dos usuários, as restrições tecnológicas, entre outras. Em outras palavras, deve considerar a estratégia de negócios que melhor satisfaça essas necessidades e seja compatível com a infraestrutura de manufatura (PUGH, 1991).

O design centrado no usuário (DCU) deve garantir que o projeto seja focado nas características e habilidades dos usuários que utilizarão o produto, levando-se em conta os aspectos físicos e psicológicos desses usuários, enquanto o design centrado no humano $(\mathrm{DCH})$ deve considerar todas as pessoas que de alguma forma se relacionam com o produto, em qualquer estágio do ciclo de vida do produto, não apenas no momento do seu uso, sendo que ambas podem incluir as áreas de usabilidade e experiência do usuário - user experience (UX) (ISO 9241-210, 2011).

Modelo, método e ferramenta são conceitos gerais, aplicados em diversas áreas, dessa forma, sua definição será baseada no dicionário, especificamente no site dictionary.com. Um modelo é "um padrão ou exemplo de imitação ou comparação". Um método é "um procedimento, técnica ou maneira de fazer algo, especialmente de acordo com um plano definido", "um procedimento, técnica ou maneira de fazer algo, especialmente de acordo com um plano definido". Portanto, esta pesquisa apresenta um estudo sobre a correlação de modelos e métodos de DCH e DCU no PDP.

A partir da análise de trabalhos clássicos e recentes (NIELSEN, 1993; JORDAN, 1998; HOM, 1998; MAGUIRE, 2001; BEVAN, 2003; HEINILÄ et al., 2005; CYBIS et al., 2007; BEVAN, 2009; ROTO et al., 2010; CAYOLA e MACIAS, 2018), e sites com detalhamentos de métodos de $\mathrm{DCH}$ e DCU (usabilidade.gov; designkit.com; ucdtoolbox.com; usabilityplanner. org), Unruh e Canciglieri Junior (2020) encontraram 89 métodos diferentes que foram categorizados em 10 tipos, e que serão utilizados neste estudo:

1) Entrevista - métodos baseados em perguntas, aplicados pessoalmente (presencialmente ou remotamente), exige interação direta dos participantes com os especialistas. Devido a se dar a partir de conversa, é ótimo para aplicação de perguntas abertas, porque permite exploração das respostas, gerando mais dados profundos para análise, e é mais adequado para análises qualitativas. A maioria das entrevistas é aplicada individualmente, com uma pessoa de cada vez, mas existem alguns métodos 
2) Questionário - métodos baseados em perguntas por meio de formulários, podendo ser preenchidos presencialmente ou remotamente, não necessitando do acompanhamento de especialistas durante sua distribuição, apenas no planejamento e análise, podendo alcançar um grande número de respostas, permite fazer análises quantitativas. Pode ser aplicado para obter informações no início de um projeto, após uma experiência ou em conjunto com outros métodos, como teste, observação e diário, por exemplo. Pode ser realizado por meio de escrita, desenho, seleção ou até foto, dependendo do objetivo. Normalmente as perguntas são sobre opiniões, experiências, percepções e/ou emoções;

3) Observação - métodos muito importantes em DCHe DCU porque permitem analisar o que as pessoas fazem (seus comportamentos). Ver as formas de agir das pessoas permite analisar a realidade, a eficácia e eficiência, e identificar necessidades que às vezes nem mesmo as pessoas sabem que têm. Sua origem está nos métodos de antropologia, e exige uma visão aberta para buscar entender a realidade observada bem como as motivações e objetivos, e uma visão crítica, para analisar a situação detalhadamente, identificando aspectos que interferem na situação, que podem ocasionar problemas, acidentes ou decepções, a partir dos quais são identificadas oportunidades de projeto;

4) Diário - métodos em que usuários usam o produto por um período em seu contexto real; durante esse tempo, os participantes preenchem um diário com informações sobre o uso e resultados do uso do produto. É muito eficiente para analisar aspectos contextuais, que só podem ser identificados no uso real, e aspectos que só aparecem com o uso prolongado. É indicado para ser aplicado no início do projeto com produtos similares, ou no final com o produto final ou protótipos de alta fidelidade funcionais;

5) Teste - métodos estruturados de observação, conduzidos por um moderador especialista. É complementado por outros métodos e analisa as métricas de usabilidade (eficácia, eficiência e satisfação) conforme a norma ISO 9241-11 (2011). É planejado por meio de um roteiro com tarefas para o participante realizar conforme os objetivos de uso do produto, funcionalidades e objetivos de pesquisa, simulando situações reais de uso que façam sentido para os participantes. No roteiro podem ser adicionadas perguntas durante as tarefas, entrevista pós-experiência e um questionário de satisfação de uso. Existem métodos individuais e métodos com mais de um usuário utilizando o produto em análise, e pode ser realizado em ambiente controlado ou em contexto real. Os objetivos desses métodos são identificar dificuldades de uso e entendimento que as pessoas possam ter com o produto;

6) Inspeção-métodosaplicadospor especialistassem participação de usuários baseado em documentos de fundamentação científica, legal ou de determinação organizacional, ou seja, listas de verificação para inspecionar a adequação do produto a requisitos pré-definidos. Pode ser feito com o produto em qualquer etapa do projeto, desde esboços iniciais do conceito do produto, protótipos de baixa fidelidade, até o produto final ou produtos similares;
7) Síntese - métodos que sintetizam informações coletadas em diversos outros métodos de análise e avaliação, além de uso do repertório dos envolvidos, pesquisas bibliográficas ou de dados disponíveis do produto. A maior parte deles é visual e permite uma visão sistêmica e de relações do produto analisado, o que auxilia muito durante o processo, porque o entendimento das informações para o desenvolvimento é facilitado;

8) Geração de ideias - métodos que auxiliam na geração de ideias com a participação de usuários, pessoas do público-alvo do produto ou stakeholders, muitas vezes chamados de métodos participativos;

9) Prototipagem/simulação - diversos autores apresentam a prototipagem como um método de $\mathrm{DCH}$, porém ele se encaixa mais como uma ferramenta ou até etapa do PDP que pode ser utilizada para vários tipos de pesquisa e análises com usuários ao longo do projeto. Os protótipos podem ser de conceito, produto, simulação física ou virtual, vídeo, papel ou outros;

10) Outros (experiências, reações e emoções) - são métodos diversos que não se encaixam em nenhum anterior, e raramente são usados sozinhos, portanto, alguns deles podem ser chamados de técnicas ou ferramentas, a maioria está relacionada à avaliação emocional, de resultado de uso ou é uma ferramenta de auxílio à outros métodos.

\subsection{Revisão da Literatura}

Com base em pesquisas preliminares desenvolvidas por Unruh e Canciglieri Jr. (2018), foi realizada uma análise detalhada de sua revisão da literatura, atualizando a mesma busca em fevereiro de 2020, com o objetivo de compreender melhor os processos de design ou desenvolvimento de produtos orientados para o ser humano, e verificar a existência e oportunidades de sistematização nos métodos de DCH e DCU no PDP.

A metodologia de revisão da literatura aplicada foi baseada em Webster e Watson (2002) e no diamante duplo (DESIGN COUNCIL UK, 2019), conforme descrito e ilustrado na figura 1, em 10 passos. O primeiro passo foi referente a definição do problema, que era obter uma visão mais concreta dos processos de design e desenvolvimento de produtos existentes, focados em seres humanos. O segundo passo foi a pesquisa preliminar exploratória, com o objetivo de identificar campos e termos principais de pesquisa.

O terceiro passo foi definido como "identificar métodos e modelos de design focados em humanos ou usuários", primeiro de um ponto de vista genérico e posteriormente na seleção de métodos e modelos orientados para o desenvolvimento de produtos. O quarto passo foi uma busca complementar para identificar os termos mais utilizados em campo, realizando alguns testes e analisando os resultados, títulos e palavras-chave em uma pesquisa exploratória.

O quinto passo foi a definição dos termos da pesquisa, dividida em duas áreas: i) ser humano e ii) desenvolvimento de produto. A primeira área era em relação ao humano e usuário relacionados ao design, onde a maioria dos termos pesquisados tinha 
o "humano" ou "usuário", e os termos mais encontrados foram: usuário, usabilidade foco no ser humano, ergonomia e fatores humanos. A segunda área era referente ao desenvolvimento de produtos, onde os termos mais citados foram: desenvolvimento de produtos, design, engenharia, modelo, método, ferramenta e técnica, todos os termos relacionados aos processos de design e desenvolvimento de produtos.

Figura 1. Processo da revisão da literatura.

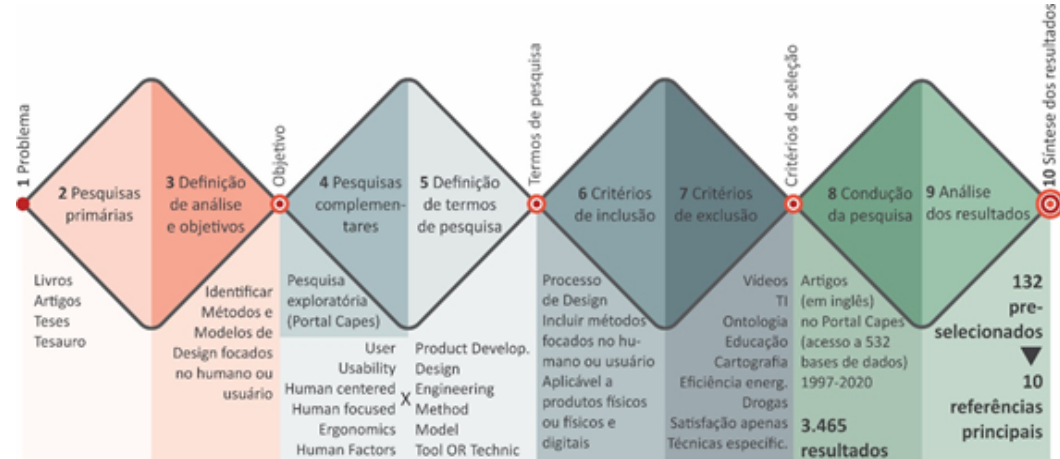

O sexto passo foi o critério de inclusão, onde foram feitas as definições de seleção dos artigos; portanto, o pensamento mais importante foi que os artigos selecionados deveriam discutir o aspecto humano ou do usuário no processo de desenvolvimento de produtos como um todo, e que tivessem proposto um modelo ou método. A sétima etapa foi a definição de critérios de exclusão, que foram definidos para a seleção de artigos que apresentassem apenas uma aplicação em um caso muito específico, técnicas muito específicas e campos não diretamente relacionados, como vídeos, cartografia, medicamentos, educação, TI e eficiência energética.

O oitavo passo foi a condução da pesquisa, realizada no Portal Brasileiro CAPES - maior portal de periódicos científicos brasileiros, com acesso a 532 bases de dados, incluindo as mais conhecidas como Web of Science, Scopus, Emerald, entre outras. A pesquisa considerou somente artigos escritos na língua inglesa e revisados por pares durante o período de 1997 a 2020. O motivo da pesquisa considerar desde a década de 90 é porque importantes estudos são oriundos daquele período.

O nono passo foi referente a análise e qualificação dos resultados, na qual a pesquisa apresentou 3.465 artigos, todos analisados em seus títulos e resumos, e 132 artigos foram selecionados de acordo com os critérios de inclusão e exclusão. Estes 132 foram completamente lidos e analisados pelos autores, chegando a uma seleção 132 foram completamente lidos e analisados pelos autores, chegando a uma seleção
restritiva de 10 artigos que apresentaram ou discutiram o desenvolvimento de produtos completo com foco no humano, sendo que alguns consideravam produtos físicos e outros digitais. Esses 10 artigos foram as principais referências utilizadas para uma análise mais profunda.

A referência de Van Kujik et al. (2007) selecionada na pesquisa foi substituída pela referência do autor principal (VAN KUJIK, 2010), porque se tratava da mesma proposta, porém mais aprofundada de sua tese de doutorado. $\mathrm{E}$ a essas dez referências foram incorporadas mais duas: i) (IDEO, 2009), que não apareceu nos resultados da revisão da literatura, mas é um dos poucos modelos de design que utiliza o termo "humano" (DCH) com mais ênfase, é um modelo amplamente aplicado no mercado, e focado em atender às necessidades das pessoas, principalmente relacionadas a situações sociais de vulnerabilidade, foi desenvolvido pela IDEO - Empresa Internacional de
Design e Inovação em associação com a Fundação Bill \& Melinda Gates, IDE (Empresa Internacional de Desenvolvimento), Heifer International (uma organização sem fins lucrativos para erradicação da pobreza e fome) e ICRW (organização de pesquisa sem fins lucrativos); ii) Reinert e Gontijo (2017) que apresentam uma sistemática de inserção da ergonomia no PDP a partir de referências da ISO 9241-210 (2011) e outras, formando uma proposta com indicações de métodos de DCH / DCU que podem ser aplicados em cada fase do PDP.

Dentre essas referências, algumas apresentam uma estrutura (framework), outras um método e outras um modelo. Com relação a aplicabilidade, constatou-se que alguns deles são inseridos no processo de desenvolvimento de forma generalizada criando produtos físicos ou digitais, outros são mais focados em desenvolvimento estrito e outros no suporte a tomada de decisão. Contudo, todas foram relevantes para este estudo, e utilizadas como embasamento para o desenvolvimento do presente artigo. A tabela 1 apresenta uma análise detalhada dessas 12 referências selecionadas enfatizando suas contribuições e limitações. 


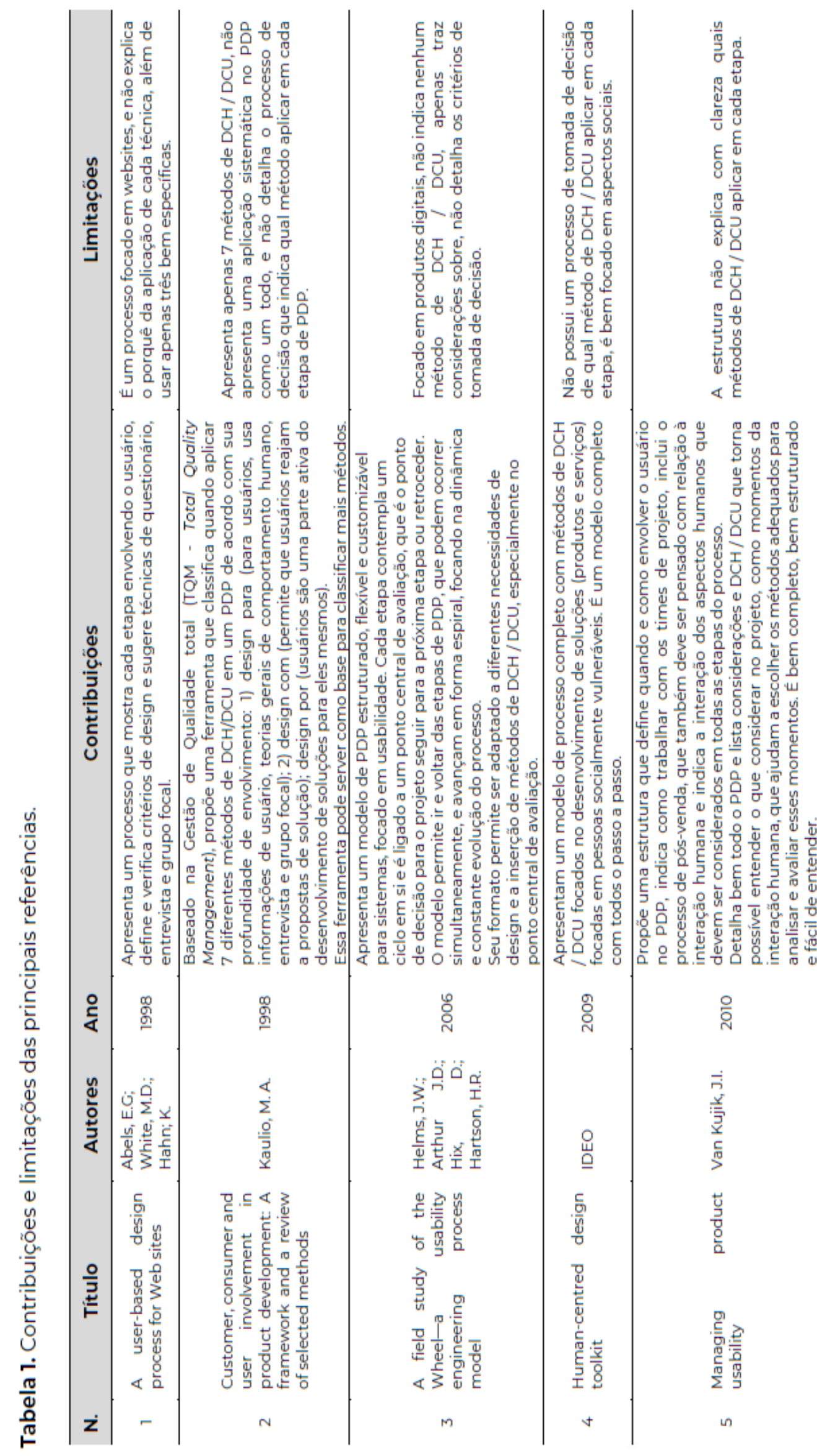

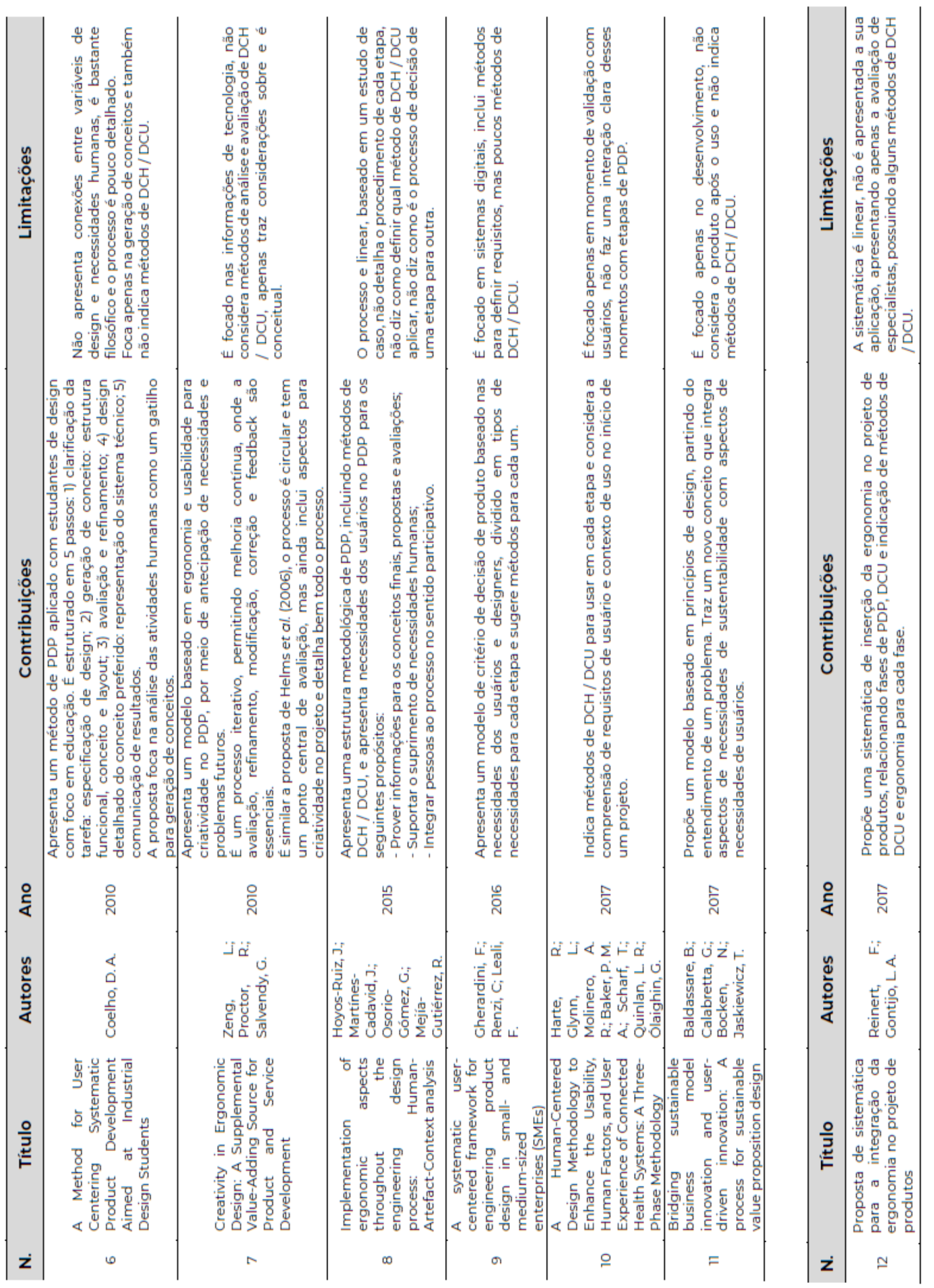


Das referências selecionadas, algumas se destacaram: o trabalho desenvolvido por Van Kujik (2010) se apresentou como um dos mais completos, uma vez que leva em consideração todas as fases do PDP, o processo de design iterativo e os aspectos do usuário. Zeng et al. (2010) exploraram a relação dos conceitos e processos de design, ergonomia e criatividade. Helms et al. (2006) desenvolveram uma estrutura dinâmica e flexível, com um ponto central de avaliação de usabilidade, um diferencial significativo de seu modelo que permite a verificação constante da adequação do produto às necessidades humanas e condução das etapas.

Outro aspecto interessante a ser destacado, é que diversas referências apresentaram processos iterativos (figura 2), cada uma contendo diferentes nomenclaturas, mas baseadas ou similares a lógica do modelo da ISO 9241-210 (2011). Esse processo pode ser repetido quantas vezes forem necessárias até que o design obtenha sua melhor versão, auxiliando na tomada de decisão e no refinamento das informações. Sua estrutura conceitual é importante para considerar a dinâmica social (DEL GLAUDIO et al., 2016), permitindo a revisão de algumas etapas de acordo com os resultados das avaliações. Esse ciclo está incluído nas pesquisas apresentadas por Van Kujik (2010), Helms et al. (2006) e Zeng et al. (2010), além de aparecer na abordagem de design globalmente conhecida e apresentada no Design Council UK (2019), na ISO 9241-210 (2011) e no estudo desenvolvido por Sebok et al. (2017)

Figura 2. Processos iterativos de design.

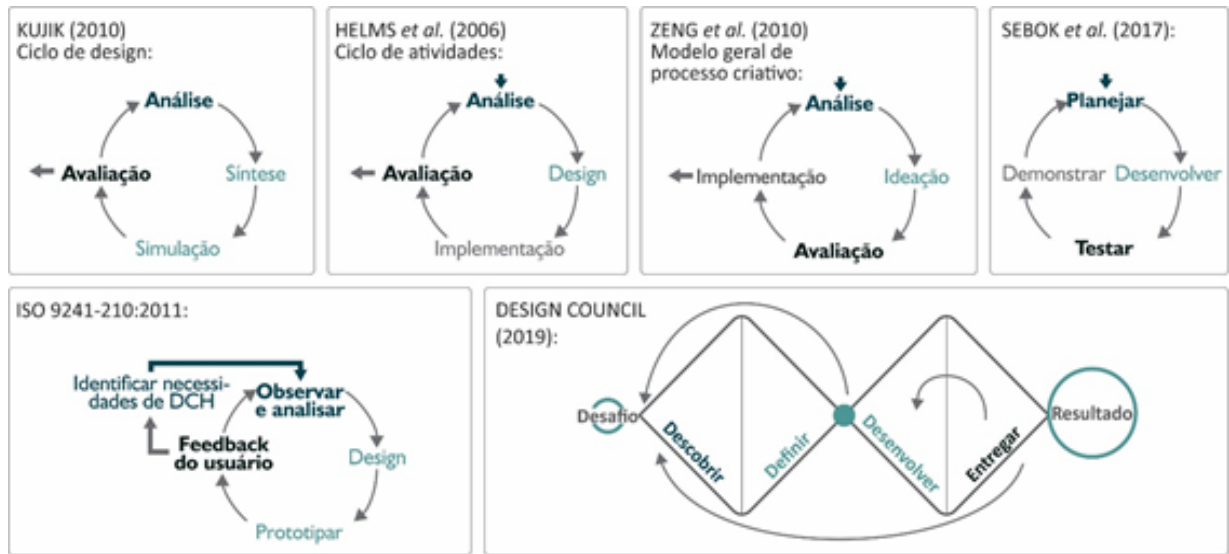

Fonte: adaptado de Van Kujik (2010), Helms et al. (2006), Zeng et al. (2010), Sebok et al. (2017), ISO 9241210 (2011) e Design Council UK (2019).

Os principais aspectos de limitação apresentados por estes trabalhos foram: ) que alguns não consideram o momento de pós uso no processo; ii) a maioria não indica ou ilustra com clareza que métodos de análise e avaliação de DCH ou DCU deve ser aplicado nas respectivas etapas do processo iterativo (figura 2); e iii) a não clareza ou indicação de quais aspectos humanos devem ser analisados ou avaliados, deixando a informação bastante subjetiva e dependente da expertise do grupo de projeto ou design do produto.

\section{PROPOSTA DO MODELO PARA ANÁLISE E AVALIAÇÃO DE NECESSIDADES} HUMANAS

Com base na análise das contribuições e limitações da revisão da literatura, foram identificados aspectos humanos que devem ser considerados nas etapas de análise e avaliação do processo de desenvolvimento de produtos (PDP), e foi criada uma estrutura conceitual, a partir da junção dessas informações ou etapas identificadas na revisão da literatura, conforme ilustrado na figura 3.

Figura 3. Estrutura conceitual de aspectos humanos no PDP.

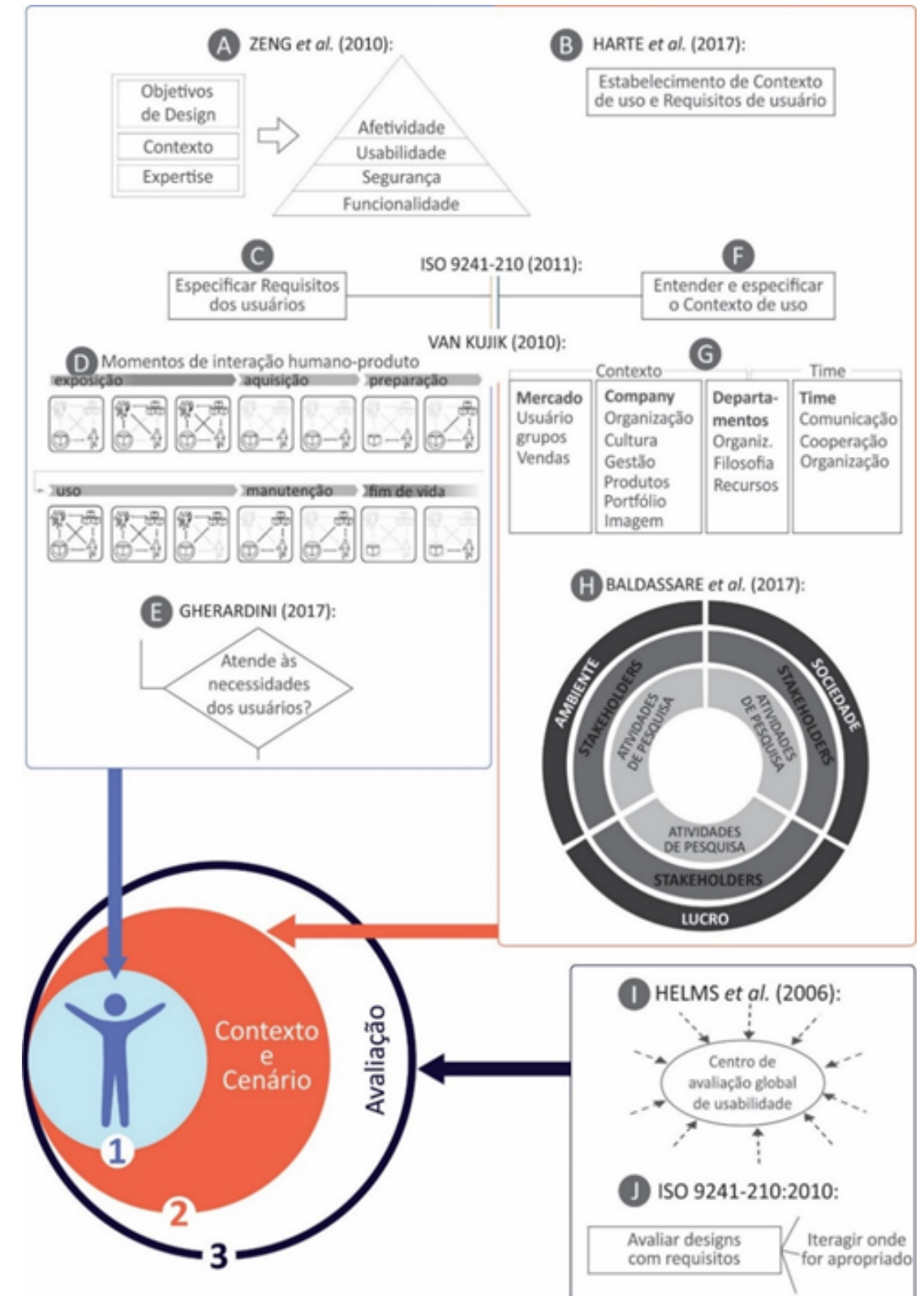

Fonte: adaptado de Zeng et al. (2010), Harte et al. (2017), ISO 9241-210, 2011, Van Kujik, (2010), Gherardini (2017) e Baldassare et al. (2017). 
A figura 3 apresenta partes das referências apresentadas anteriormente podendo ser dividida em 3 partes, duas delas levando em consideração os aspectos humanos que devem fazer parte em um PDP (ser humano, contexto ou cenário) e a terceira considerando a avaliação onde devem ser aplicados os métodos de avaliação desses aspectos durante o desenvolvimento de produtos, auxiliando no processo de tomada de decisões referente a adequação do produto, analisando o público alvo que irá utilizar o produto.

Para formar a primeira parte que está relacionada ao entendimento das características e comportamentos das pessoas que utilizarão o produto (características físicas e cognitivas, preferências, sentidos, e comportamentos) no início de um projeto de design, é importante analisar e definir os seguintes aspectos (figura 3): i) ergonômicos, incluindo afetividade, usabilidade, segurança e funcionalidade (ZENC et al., 2010 - detalhe "A"); ii) requisitos do usuário (HARTE et al., 2017 - detalhe "B" e ISO 9241-210, 2011 - detalhe "C"); iii) momentos de interação homem-produto, incluindo desde o momento em que o usuário conhece o produto até seu uso e descarte (VAN KUJIK, 2010 - detalhe "D"); e iv) necessidades do usuário (GHERARDINI, 2017 - detalhe "E").

A segunda parte é um complemento à primeira, porque diz respeito ao contexto de uso, ou seja, onde os comportamentos humanos acontecem, e inclui os aspectos relacionados a: i) interação humana com o produto (ZENG et al., 2010 - detalhe "A"; HARTE et al., 2017 - detalhe "B"; e ISO 9241-210, 2011 - detalhe "F"); ii) contexto de mercado e empresa (VAN KUJIK, 2010 - detalhe "G"); e iii) ambiente, sociedade e lucro (BALDASSARE et al., 2017 - detalhe " $\mathrm{H}$ ").

A terceira parte da estrutura conceitual, onde todas essas informações devem ser usadas é a avaliação do produto durante o desenvolvimento, onde métodos de $\mathrm{DCH}$ e DCU também podem ser aplicados para avaliar a adequação do produto aos requisitos das pessoas em foco, conforme ilustrado nos detalhes "l" e "J" da figura 3 respectivamente (HELMS et al., 2006; ISO 9241-210, 2011).

Helms et al. (2006) e Szabluk et al. (2019) enfatizaram a importância da iteratividade e flexibilidade dos processos de design de produtos focados no humano. Essa estrutura poderia ser utilizada de forma dinâmica em qualquer PDP e, portanto, poderia ser o ponto de partida de todo o desenvolvimento de produto orientado ao humano, e o ponto de referência para avaliação do produto levando em consideração os requisitos humanos.

A partir da estrutura conceitual, foi desenvolvida uma proposta de modelo com - objetivo de contribuir com as lacunas e oportunidades identificadas na literatura. É importante atestar que as informações humanas em um PDP são os propulsores do processo de iteração proporcionando melhoria da qualidade e consistência nas informações do projeto (HELMS et al., 2006; ISO 9241-210, 2011; SZABLUK et al., 2019).

Como resultado, os requisitos humanos devem ser considerados durante todo o processo, podendo atualizar as informações necessárias de maneira simultânea de acordo com o avanço do projeto. Isso só é possível devido ao fato do modelo HUNE possuir uma estrutura dinâmica o que possibilita a iteração com os requisitos e o PDP.

As informações humanas podem ser compostas por vários elementos de naturezas diferentes, como: i) características humanas; ii) sentidos humanos (usados para interagir com qualquer coisa); iii) comportamento humano; iv) contexto; e v) cenário de uso do produto. Esses elementos reunidos formam conceitualmente uma célula como ilustrado na figura 4. De acordo com o significado, uma célula é um dos vários compartimentos que fazem parte de um todo, ou biologicamente é a unidade estrutural básica de todos os organismos, desta forma, nesta pesquisa ela foi considerada a referência base da estrutura do modelo, representando esses elementos de forma dinâmica e não linear, respeitando o comportamento dos fatores humanos.

Figura 4. Proposta de modelo HUNE.

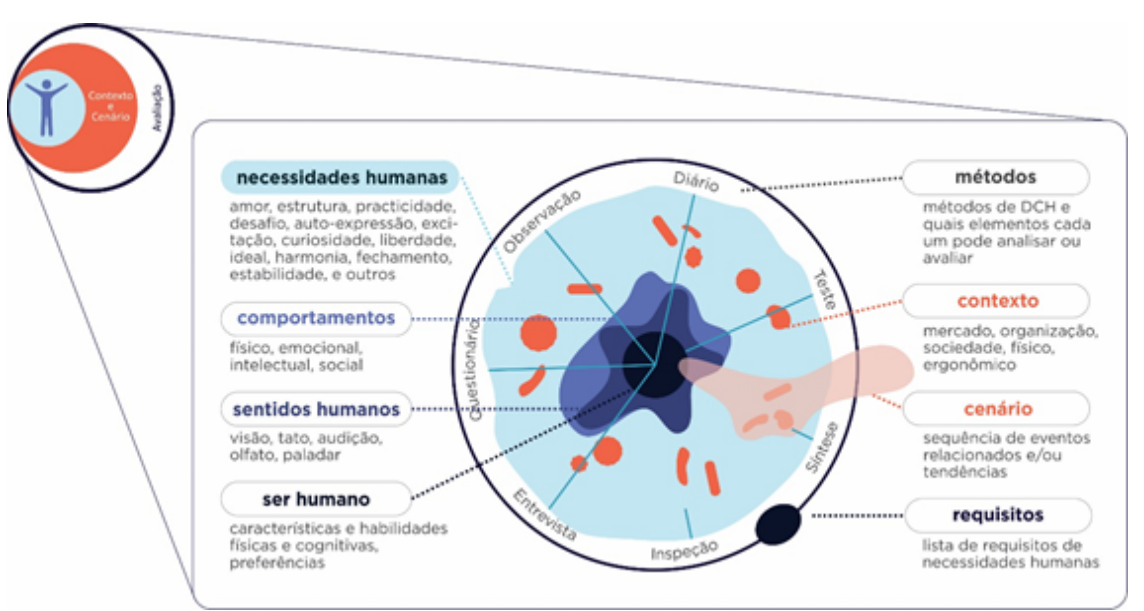

Fonte: Unruh (2020)

O nome dado ao modelo foi "HUNE" (HU - humano, NE - necessidades) e é constituído de 8 elementos ( 6 referentes aos aspectos humanos que podem ser analisados ou avaliados, uma lista de requisitos e os tipos de métodos de DCH e DCU que podem auxiliar nessas análises e avaliações):

1) Necessidades Humanas: as necessidades humanas são a base do modelo porque novos produtos são criados para atender necessidades humanas (BENNETT e MCWHORTER, 2019), são o foco dos projetos do DCH (GHERARDINI, 2017) e estão diretamente relacionados ao desenvolvimento sustentável (BALYEIJUSA, 2019);

2) Ser Humano: é importante considerar o ser humano por quem ele é primeiro, porque suas características afetam seus comportamentos e necessidades; esse elemento considera aspectos corporais como antropometria e biomecânica (IIDA 2005), sistema cognitivo, diferenças individuais e preferências (PONCIANO et al., 2014), uma vez que a teoria do apego ao produto sugere que as pessoas desenvolvam o apego ao produto para ajudá-las na construção ou manutenção do aspecto de auto identidade (ORTH et al., 2018);

3) Sentidos Humanos: os sentidos fazem parte do ser humano (PONCIANO et al., 2014), e decidiu-se distingui-lo em um elemento separado, porque é a interface humana para interação com o mundo e as coisas exteriores, e pode interferir em algumas definições de design

4) Comportamentos: podem ser considerados todos os momentos de interação humano-produto (VAN KUJIK, 2010), aspectos ergonômicos relacionados a ações, como 
usabilidade e funcionalidade (ZENG et al., 2010), comportamento social e emoções (PONCIANO et al., 2014);

5) Contexto: é um importante ponto de partida de um projeto de design e crucial para considerar o usuário, porque seus comportamentos estão diretamente ligadas com o sistema e contexto (SZALUK et al., 2019), inclui todos os aspectos relacionados ao contexto de uso (ZENG et al., 2010, HARTE et al., 2017, ISO 9241-210, 2011), contexto de mercado empresa (VAN KUJIK, 2010), ambiente, sociedade e lucratividade (BALDASSARE et al. 2017);

6) Cenário: o cenário é uma descrição do que os usuários fazem enquanto usam alguma coisa (LEE et al., 2011) e pode estar relacionado a comportamentos humanos, comportamentos de produtos, tendências e outros fatores não humanos, ou seja, liga diversos dos elementos anteriores:

7) Requisitos: baseados em Gherardini et al. (2016), recomenda-se construir uma lista de requisitos como uma síntese de todas as informações humanas reunidas no início de um projeto, com um nível de importância de cada requisito a ser avaliado durante o desenvolvimento do projeto, assim as informações humanas que obtiveram requisitos podem ser verificadas na fase de avaliação do PDP, ajudando a definir se o projeto atende às necessidades humanas e pode avançar no processo ou se o projeto deve ser revisado em algum aspecto. É ilustrado como um receptor na célula, porque é o que gera a comunicação entre os aspectos humanos e o projeto do produto;

8) Métodos: os métodos que podem ser aplicados para análise e avaliação dos aspectos humanos durante o PDP, conforme apresentado no item 2 deste artigo, podem ser classificados em 10 categorias principais de métodos de DCH e DCU, sendo que desses, 7 podem ser considerados para análise e avaliação nesse modelo; já que a geração de ideias e prototipagem são mais voltadas ao desenvolvimento estrito, para que a análise e avaliação possa ser aplicada, e os "outros" métodos podem ser aplicados em conjunto com os de análise e avaliação como complementos. Estes 7 foram analisados e classificados, pois podem ser utilizados para cada elemento de informação no modelo HUNE, conforme indicado na tabela 2. Na figura 3, esses métodos aparecem ao redo da célula porque são a maneira de acessar informações humanas para projetos de desenvolvimento de produtos, e a linha proveniente de cada método representa a faixa de profundidade em que podem ser analisados.
Tabela 2. Métodos de DCH e DCU e possíveis aspectos que podem analisar.

\begin{tabular}{|c|c|c|c|c|c|c|c|}
\hline \multirow{2}{*}{ Elemento } & \multicolumn{7}{|c|}{ Tipos de método de DCH e DCU } \\
\hline & Questlonárı & Entrevista & observaçăo & Dlárlo & Teste & Inspeçāo & Sintese \\
\hline Ser humano & $\checkmark$ & $\checkmark$ & $\checkmark$ & $\checkmark$ & & & \\
\hline $\begin{array}{c}\text { Necessidades } \\
\text { humanas }\end{array}$ & $\checkmark$ & $\checkmark$ & $\checkmark$ & $\checkmark$ & & & \\
\hline Sentidos humanos & $\checkmark$ & $\checkmark$ & $\checkmark$ & $\checkmark$ & $\checkmark$ & $\checkmark$ & \\
\hline Comportamentos & $\checkmark$ & $\checkmark$ & $\checkmark$ & $\checkmark$ & $\checkmark$ & & \\
\hline Contexto & $\checkmark$ & $\checkmark$ & $\checkmark$ & $\checkmark$ & $\checkmark$ & $\checkmark$ & \\
\hline Cenário & $\checkmark$ & $\checkmark$ & $\checkmark$ & $\checkmark$ & $\checkmark$ & $\checkmark$ & $\checkmark$ \\
\hline Inter-relações & $\checkmark$ & $\checkmark$ & $\checkmark$ & $\checkmark$ & $\checkmark$ & $\checkmark$ & $\checkmark$ \\
\hline
\end{tabular}

A estrutura do modelo HUNE pode iterar com modelos, métodos ou estruturas de PDP, porque pode ser configurada em conjunto com diferentes processos para conduzir a consideração das necessidades humanas no processo de design ou desenvolvimento. Para fazer essa conexão com o PDP, o modelo deve ser estruturado em uma configuração circular iterativa, de forma que possa servir como suporte aos momentos de análise (etapas iniciais de um projeto ou de uma etapa) e avaliação (etapas mais avançadas de um projeto ou etapa) do ciclo iterativo de design (figura 2), como mostra a figura 5, que como um exemplo da estrutura de conexão, considera as quatro principais etapas básicas de um PDP (pré-desenvolvimento, desenvolvimento, produção e vendas, produto em uso).

Figura 5. Conexão do modelo HUNE com o processo iterativo da ISO 9241-210 (2011).

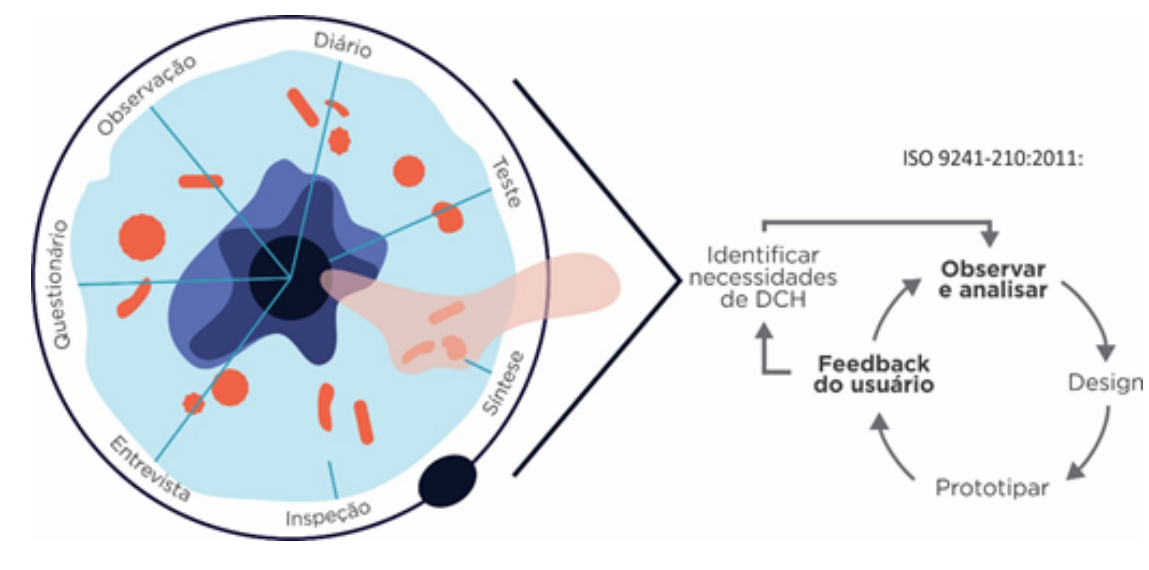

Fonte: Unruh (2020).

\section{APLICAÇÃO DO MODELO HUNE}

A partir da proposta do modelo HUNE (figura 4), se fez necessária sua aplicação e validação utilizando casos reais de desenvolvimento de produto orientado e centrado no ser humano. $O$ modelo foi aplicado em dois casos, desenvolvidos por 8 estudantes 
e profissionais num curso de mestrado e doutorado em engenharia de produção e sistemas, sendo 6 deles graduados e com prática profissional em design de produto e 2 graduados em engenharia e com prática profissional em projetos de engenharia.

Para este estudo, foram escolhidos 2 produtos de uma indústria brasileira de cosméticos aplicando o modelo em um PDP, seguindo a recomendação do processo iterativo de design (VAN KUJIK, 2010; HELMS et al., 2006; ZENG et al., 2010; SEBOK et al., 2017; ISO 9241-210, 2011; DESIGN COUNCIL UK, 2019), por meio de aplicação do modelo com métodos de análise de DCH no início do projeto, avaliação no meio e no final do projeto.

O primeiro caso foi o desenvolvimento de uma embalagem de sabonete (figura 6) e, o segundo, uma máscara de cílios (figura 7). Ambos os estudos tiveram seus inícios com a análise dos aspectos humanos obtidos por meio da aplicação de métodos de questionário, observação e inspeção (análise de produtos concorrentes) a fim de identificar informações referentes as características humanas, necessidades, contexto e cenário, para subsidiar a formulação da estratégia de design. Em ambos os casos foi criado um mapa de jornada do usuário (método de síntese) e a lista de requisitos de necessidades humanas para o produto.

Figura 6. Caso de embalagem de sabonete.

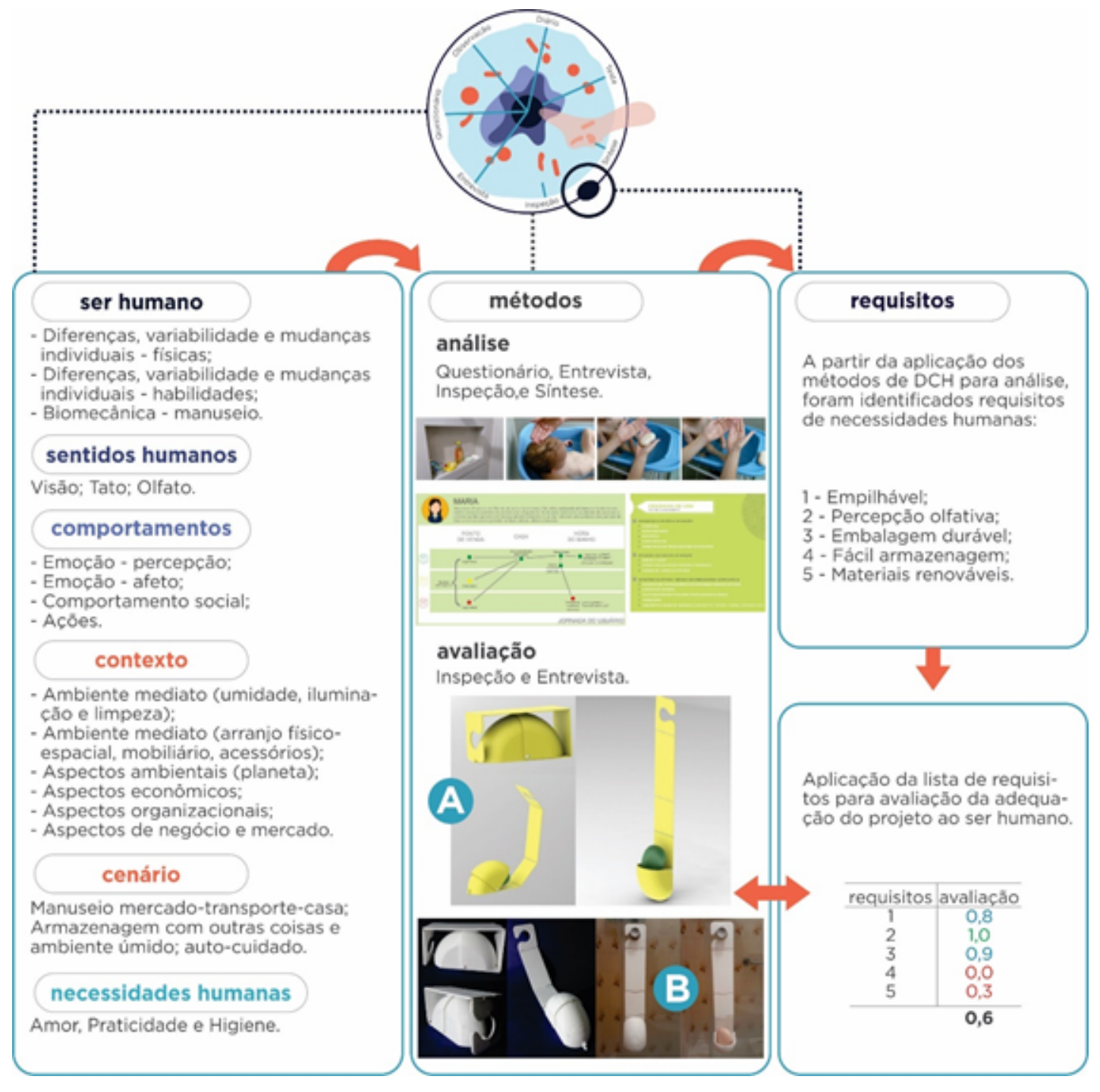

Depois de obter todas as informações necessárias, foram desenvolvidos conceitos e ideias de produto, os quais foram avaliadas por meio do método de questionário de avaliação de conceitos com pessoas do perfil alvo do produto e verificação da lista de requisitos, onde foi atribuída uma pontuação a cada requisito para verificar se o produto era ou não adequado aos requisitos identificados no início. Com esse processo, foi possível obter algumas ideias focadas em melhorias no projeto e então foi possível desenvolver um protótipo. O último passo foi a avaliação do protótipo, também por meio da lista de requisitos e por meio dos métodos de observação de uso e entrevista. De acordo com as opiniões dos profissionais participantes, ambos os casos foram considerados aprovados e alinhados com as necessidades humanas. Para o primeiro caso experimental foi desenvolvida uma embalagem de sabonete que tivesse duas funções básicas, que são: i) ser um contêiner para armazenamento do sabonete (detalhe "A" da figura 6); ii) servir de saboneteira com um suporte para se pendurar na manopla do chuveiro, onde os usuários do produto poderiam usá-lo em uma viagem, por exemplo, ou durante o banho (detalhe "B" da figura 6).

Para o segundo caso foi desenvolvida uma nova embalagem de máscara de cílios que permitisse aos usuarios usá-la sem sujar suas mãos e dedos, e ainda pudesse se recarregada o seu conteúdo sem alterar o corpo do produto, economizando assim a matéria prima (detalhe " $A$ " da figura 7).

Figura 7. Caso de máscara de cílios.

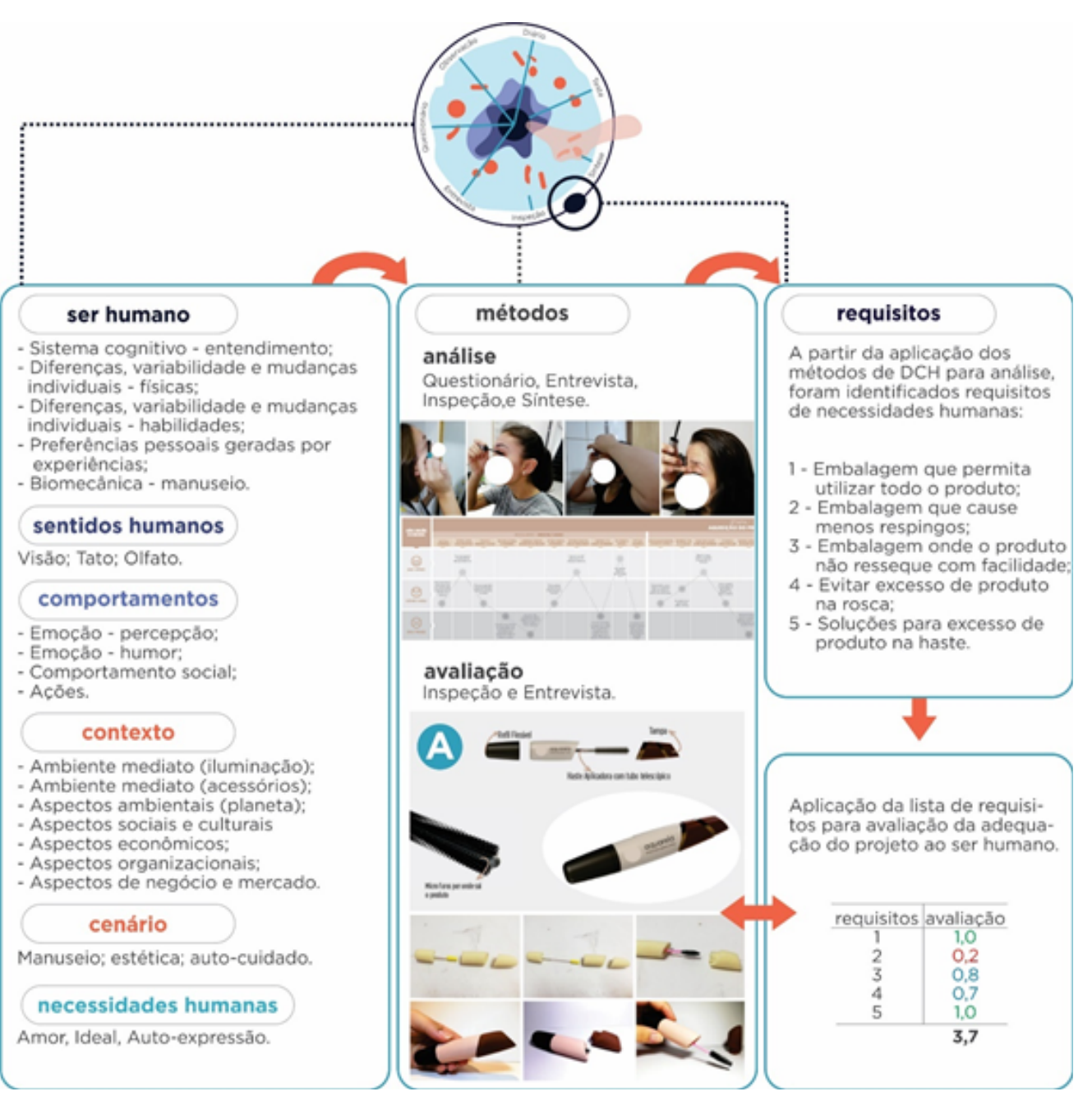


Após a aplicação, os profissionais que aplicaram os casos contribuíram ainda avaliando o modelo, e os resultados foram positivos e promissores, atestando que o processo foi relevante e fácil de se aplicar, a lista de requisitos se mostrou bastante útil, objetivo, completo, envolvente, de fácil entendimento e aplicação, estruturado e assertivo para identificar e avaliar melhor às necessidades humanas que devem ser consideradas e tratadas durante o processo de design.

As dificuldades identificadas foram na análise subjetiva dos dados e maneira de aplicar os métodos de DCH/DCU. Alguns participantes ficaram um pouco confusos com relação de quais aspectos exatamente analisar e levar em consideração em cada elemento do modelo, e na escolha de como fazer as perguntas e análises corretas na aplicação dos métodos.

\section{DISCUSSÃO}

Da análise da literatura foi possível observar que existem modelos e métodos de PDP estruturados sem a necessidade de se propor mais um novo modelo. Porém, ficou evidente que existe carência de uma sistematização mais focada em aspectos humanos a serem considerados nas etapas de análise e avaliação no ciclo iterativo de design, daí o motivo de se ter criado uma estrutura conceitual para análise e avaliação de necessidades humanas (figura 3). Isso foi possível, uma vez que as referências relevantes encontradas na revisão da literatura, em conjunto com os elementos da estrutura e os tipos de métodos de DCH/DCU evidenciaram as contribuições e limitações das pesquisas na área, resultando na construção do modelo HUNE.

O modelo HUNE foi criado a partir de pesquisas existentes, relacionando e organizando as informações e contribuições de diferentes autores com relação a produtos focados no ser humano. $O$ modelo foca na orientação para análise e avaliação de aspectos de necessidades humanos, incluindo os aspectos físicos e cognitivos humanos (IIDA, 2005; PONCIANO et al., 2014), sentidos humanos (PONCIANO et al., 2014), comportamentos com relação a interação humano-produto (VAN KUJIK, 2010; ZENG et al., 2010; PONCIANO et al., 2014), contexto de uso ((SZALUK et al., 2019), contexto de uso (ZENG et al., 2010; HARTE et al., 2017; ISO 9241-210, 2011; BALDASSARE et al., 2017), cenário (LEE et al., 2011) e meios de acessar essas informações em projetos específicos, que são os requisitos de necessidades humanas identificados a partir da aplicação de métodos de DCH/DCU (NIELSEN, 1993; JORDAN, 1998; HOM, 1998; MAGUIRE, 2001; BEVAN, 2003; HEINILÄ et al., 2005; CYBIS et al., 2007; BEVAN, 2009; ROTO et al., 2010; CAYOLA e MACIAS, 2018).

Portanto, considerar o ser humano no PDP é complexo e muitas vezes subjetivo, e o modelo HUNE demonstrou-se útil na organização dessas informações de forma flexível e adaptável a contextos específicos de projeto, sendo que a formação de requisitos a partir de métodos de $\mathrm{DCH} / \mathrm{DCU}$ e suas avaliações posteriores no projeto auxiliarão o processo decisório com relação a orientação ao ser humano.

Embora esta pesquisa não tenha explorado especificamente e cientificamente os temas inovação social e sustentabilidade, ficou evidente que o modelo proposto, uma vez que contribui para o desenvolvimento de produtos focado nas necessidades humanas, o que é coerente com o foco na melhoria da qualidade de vida das pessoas e no desempenho econômico organizacional (BENNETT e MCWHORTER, 2019; BALYEIJUSA 2019), quando aplicado na sua forma integral, contribuirá para os dois temas.

As aplicações dos dois casos experimentais abordados nesta pesquisa foram até etapas iniciais de um PDP, pois foi possível avaliar apenas as contribuições na construcão de requisitos e na avaliação de protótipos de baixa fidelidade mas os resultados encontrados já se mostram promissores e cumpriram com o objetivo de auxiliar na análise e avaliação das necessidades humanas.

\section{CONCLUSÃO}

Esta pesquisa apresentou a proposta de um modelo de análise e avaliação das necessidades humanas para o suporte ao processo de desenvolvimento de produtos. Incialmente analisou-se modelos, métodos e estruturas de PDP focados no humano com o intuito de identificar suas contribuições e limitações cientificas. Baseado nesta análise, criou-se o modelo HUNE capaz de identificar aspectos e necessidades humanas no processo de desenvolvimento de produtos (PDP).

O modelo HUNE é original e relevante porque leva em consideração aspectos importantes das necessidades humanas e do ser humano, aspectos importantes estes, para auxílio no processo decisório nas atividades de projeto. Trabalha em conjunto com a indicação dos tipos de métodos de DCH/DCU em uma estrutura clara e orgânica, podendo ser conectada e integrada a diferentes modelos, métodos e estruturas de PDP existentes. Com isso, consegue-se promover a iteratividade e contribuir com estudos existentes, em vez de tentar substituí-los. Dessa forma o produto terá maiores chances de satisfazer as pessoas a quem é projetado, possivelmente gerando retornos positivos para a organização.

Acredita-se que a aplicação do modelo a médio ou longo prazo em empresas que desenvolvem produtos, possa contribuir com aspectos sociais e de sustentabilidade organizacionais e da sociedade em si, trazendo benefícios para ambos (empresas e usuários). Estes aspectos sociais e de sustentabilidade não puderam ser explorados cientificamente nesta pesquisa, uma vez que para isso, teria que haver o lançamento do produto no mercado e um período após o lançamento, de forma que o impacto pudesse ser medido após o uso do produto por um período de tempo, por pessoas do público-alvo. Todavia, os autores acreditam que a comprovação destes benefícios (sociais e de sustentabilidade) se dará com a continuidade da pesquisa exploradas em estudos futuros.

Estudos futuros podem também contribuir com a criação de documentos detalhados para cada elemento do modelo, aplicação e validação, análise de sua aplicação com outros modelos, métodos ou estruturas, como, por exemplo, a bússola de formação empática para codesign de Smeenk et al. (2019). Para isso, seria importante aplicar diversas células HUNE de forma conjunta, sendo cada uma focada em um perfil de pessoas podendo interagir com o produto (stakeholders), fortalecendo o conceito de DCH/DCU como um todo, e analisar quais outros aspectos em um PDP podem ser considerados como células, formando um aglomerado de células com diferentes com funções e objetivos específicos que podem ser criados de forma integrada. 


\section{AGRADECIMENTOS}

Os autores gostariam de agradecer à Pontifícia Universidade Católica do Paraná (PUCPR), ao Programa de Pós-Graduação em Engenharia de Produção e Sistemas (PPGEPS/PUCPR), ao Conselho Nacional de Desenvolvimento Científico e Tecnológico (CNPq) e a Coordenação de Aperfeiçoamento de Pessoal de Nível Superior (CAPES) pelo apoio financeiro para realização desta pesquisa.

\section{REFERÊNCIAS}

ABELS, Eileen G.; WHITE, Marilyn Domas; HAHN, Karla. A user-based design process for Web sites, Internet Research: Electronic Networking Applications and Policy, $v$. 8, p. 39-48, 1998

ALHARTHI, Rajwa, GUTHIER, Benjamin, \& EL SADIK, Abdulmotaleb. Recognizing Human Needs During Critical Events Using Machine Learning Powered PsychologyBased Framework. IEEE Access, v. 6, p. 58737 - 58753, 2018.

BALDASSARE, Brian; CALABRETTA, Giulia; BOCKEN, Nancy; JASKIEWICZ, Tomasz. Bridging sustainable business model innovation and user-driven innovation: $A$ process for sustainable value proposition design. Journal of Cleaner Production, $v$. 147, p. 175-186, 2017.

BALEIJUSA, Senkosi Moses. Sustainable Development Practice: The Central Role of the Human Needs Language. Social Change, v. 49, n. 2, p. 293-309, 2019.

BENNETT, Elisabeth E.; MCWHORTER, Rochell R. Social Movement Learning and Social Innovation: Empathy, Agency, and the Design of Solutions to Unmet Social Needs. Advances in Developing Human Resources, v. 21, n. 2, p. 224-249, 2019.

BEVAN, Nigel. UsabilityNet Methods for User Centered Design. Human-Computer Interaction: Theory and Practice, proceedings of $\mathrm{HCl}$ International, v. 1, n. 1 p. 434438, 2003.

BEVAN, Nigel. Criteria for selecting methods in user-centered design. Workshop paper I-USED, 2009

BRÖDNER, Peter. Reflective design of technology for human needs. Al \& Soc, 25th anniversary volume, a faustian Exchange: what is to be human in the era or ubiquitous technology? v. 28, p. 27-37, 2013.

CAYOLA, Luis; MACÍAS, José A. Systematic guidance on usability methods in usercentered software development. Information and Software Technology, v. 97, p. 163$175,2018$.

CHOI, Youngok; NA, Jea Hoo; WALTERS, Andrew; LAM, Busayawan; BOULT, John, JORDAN, Patrick W.; GREEN, Stephen. Design for social value: using design to improve the impact of CSR. Journal of Design Research, v. 16, n. 2, p. 155-174, 2018.

COELHO, Denis A. A Method for User Centering Systematic Product Development Aimed at Industrial Design Students, Design and Technology Education: An International Journal, 2010.

CYBIS, Waler; BETIOL, Adriana Holtz.; FAUST, Richard. Ergonomia e Usabilidade: conhecimentos, métodos e aplicações. São Paulo: Novatec Editora, 2007.

DECl, Edward L.; RYAN, Richard M. The "what" and "why" of goal pursuits: human needs and the self-determination of behavior. Psychol. Inq., v. 11, p. 227-268, 2000.

DEL GAUDIO, Chiara; FRANZATO, Carlo; DE OLIVEIRA, Alfredo Jefferson. Hope against hope: tackling social design. Journal Design Research, v. 14, n. 2, p. 119-141, 2016.

DESIGN COUNCIL UK. The Design Process: What is the Double Diamond? set. 2019. Disponível em: https://www.designcouncil.org.uk/news-opinion/double-diamond-15years. Acesso em: 03 mar. 2020.

FLICK, Uwe. Qualidade na pesquisa qualitativa. Porto Alegre: Bookman, Artmed, 2009 GIL, Antoni Carlos. Como elaborar projetos de pesquisa. 5 ed. São Paulo: Atlas, 2010

GHERARDINI, Francesco; RENZI, Cristina; LEALI, Francesco. A systematic user-centered framework for engineering product design in small- and medium-sized enterprises (SMEs), International Journal of Advanced Manufacturing Technology, v. 91, p. 1723$1746,2016$.

HARTE, Richard; GLYNN, Liam; RODRÍGUEZ-MOLINERO, Alejandro; BAKER, Paul M. A.; SCHARF, Thomas; QUINLAN, Leo R; OLAIGHIN, Gearóid. A Human-Centered Design Methodology to Enhance the Usability, Human Factors, and User Experience of Connected Health Systems: A Three-Phase Methodology. JMIR Human Factors, v. 4, n. 1, 2017.

HEINILÄ, Juhani; STRÖMBERG, Hanna; LEIKAS, Jaana; IKONEN, Veikko; IIVARI, Netta; JOKELA, Timo; AIKIO, Kari-Pekka; JOUNILA, Ilari; HOONHOUT, Jettie; LEURS, Natasja. User Centered Design: Guidelines for Methods and Tools. The Nomadic Media consortium, 2005.

HELMS, James W.; ARTHUR, James D.; HIX, Deborah; HARTSON, H. Rex. A field study of the Wheel-a usability engineering process model, The Journal of Systems \& Software, v. 79, p. 841-858, 2006.

HOM, James. The Usability Methods Toolbox Handbook, 1998. Disponível em: http:// jthom.best.vwh.net/usability/usable.htm. Acesso em: 22 set. 2018.

HOYOS-RUIZ, Julián; MARTÍNEZ-CADAVID, José Fernando; OSORIO-GÓMEZ, Gilberto; MEJÍA-GUTIÉRREZ, Ricardo. Implementation of ergonomic aspects throughout the engineering design process: Human-Artefact-Context analysis, International Journal

HFD, v.9, n 18, p. 52-77, dezembro 2020 
on Interactive Design and Manufacturing, v. 11, p. 263-277, 2015.

IDEO. Human Centered Design Toolkit, 2009. Disponível em: https://www.designkit. org/methods. Acesso em: 03 mar. 2020.

IIDA, Itiro. Ergonomia: Projeto e Produção. $2^{a}$ ed. São Paulo: Edgad Blücher, 2005.

ISO 9241-210:2010. Ergonomia da interação humano-sistema, Parte 210: Projeto centrado no ser humano para sistemas interativos, 2011.

ISO 9241-11:2011. Requisitos ergonômicos para o trabalho com dispositivos de interação visual

Parte 11: Orientações sobre usabilidade, 2011.

JORDAN, Patrick W. An Introduction to Usability. London: Taylor \& Francis Ltda, 1998. KAULIO, Matti. Customer, consumer and user involvement in product development: A framework and a review of selected methods, Total Quality Management, v. 9, n. 1, p. 141-149, 1998.

KISPAL-VITAL, Zsuzsanna. Comparative analysis of motivation theories. International Journal of Engineering and Management Sciences (IJEMS), v. 1, n.1, 2016.

KOLUS, Ahmet; WELLS, Richard; NEUMANN, Patrick. Production quality and human factors engineering: A systematic review and theoretical framework. Applied Ergonomics, v. 73, p. 55-89, 2018

LEE, Kwang II; JIN, Beom Suk; JI, Yong Gu. The Scenario-Based Usability Checklist Development for Home Appliance Design: A Case Study. Human Factors and Ergonomics in Manufacturing \& Service Industries, v. 21, n. 1, p. 67-81, 2011

MAGUIRE, Martin. Methods to support human-centered design. International Journal of Human-Computer Studies, v. 55, p. 587-634, 2001.

MELO, Paulo; JORGE, Luísa. Quantitative support for UX methods identification: how can multiple criteria decision making help? Universal Access in the Information Society, v. 14, p. 215-229, 2015.

NIELSEN, Jacob. Usability Engineering. San Diego: Morgan Kaufmann, 1993.

ORTH, Daniel, THURGOOD, Clementine; VAN DEN HOVEN, Elise. Designing objects with meaningful associations. International Journal of Design, v. 12, n. 2, p. 91-104, 2018

PONCIANO, Lesandro; BRASILEIRO, Francisco.; ANDRADE, Nazareno; SAMPAIO, Livia. Considering human aspects on strategies for designing and managing distributed human computation. Journal of Internet Services and Applications, v. 5, n. 10, 2014.
PUGH, S. Total Design: integrated methods for successful product engineering. Massachusetts: Addison Wesley, 1991.

REINERT, Fabíola; GONTIJO, Leila Amaral. Proposta de sistemática para a integração da ergonomia no projeto de produtos. Human Factors in Design, v. 6, n. 12, p. 105-123, 2017.

ROTO, Virpi; LEE, Ming; PIHAKALA, Kari; CASTRO, Brenda; VERMEEREM, Arnold; LAW, Effie; VÄÄNÄNEN-VAINIO-MATTILA, Kaisa; HOONHOUT, Jettie; OBRIST, Marianna. All UX Evaluation methods. All About UX. Disponível em: http://www.allaboutux.org/. Acesso em 22 set. 2018.

RYAN, Richard M., DECl, Edward L. On Happiness and Human Potencials: A Review of Research on Hedonic and Eudaimonic Well-Being. Annual Review of Psychology, $v$. 52, p. 141-166, 2001.

SMEENK, Wina, STURM, Janienke; EGGEN, Berry. A comparison of existing frameworks leading to an empathic formation compass for co-design. International Journal of Design, v. 13, n. 3, p. 53-68, 2019.

SZABLUK, Daniela; BERGER, Ana Von F.; CAPA, Andrea; DE OLIVEIRA, Manuela F. Design de experiências aplicado à pesquisa: um método exploratório de pesquisa centrada no Usuário. Human Factors in Design, v. 8, n. 15, p. 98-113, 2019.

UNRUH, Gabriela Unger; CANCIGLIERI JR., Osíris. Human and User-Centered Design Product Development: A Literature Review and Reflections. Advances in Transdisciplinary Engineering, IOS Press, v. 7, p. 211-220, 2018

UNRUH, Gabriela Unger; CANCIGLIERI JUNIOR, Osíris. Identifying and Classifying Human-Centered Design Methods for Product Development. Human Systems Engineering and Design II, Advances in Intelligent Systems and Computing, V. 1026, p. 435-455, 2020 .

UNRUH, Gabriela Unger. Modelo de análise e avaliação de necessidades humanas para o desenvolvimento de produtos - HUNE. Tese (Doutorado) - Programa de pósgraduação em Engenharia de produção e sistemas, Pontifícia Universidade Católica do Paraná, 2020.

VAN KUJIK, Jasper. Managing Product Usability: How companies deal with usability in the development of electronic consumer products. Netherlands, 2007. Tese (Doutorado) - Delft University of Technology, Faculty of Industrial Design Engineering.

VAN KUJIK, Jasper; CHRISTIAANS, Henri; KANIS, Heimrich; EIJK, Daan van. Usability in Product Development: a conceptual framework, Proceedings of the Ergonomics Society Annual Conference, Contemporary Ergonomics Nottingham, UK, 2007.

VINCENT, Christopher James; LI, Yunqiu; BLANDFORD, Ann. Integration of human factors and ergonomics during medical device design and development: It's all about communication. Applied Ergonomics, v. 45, p. 413-419, 2014.

HFD, v.9, n 18, p. 52-77, dezembro 2020 
WEBSTER, Jane; WATSON, Richard T. Analyzing the past to prepare for the future: writing a literature review. MIS Quarterly \& The Society for Information Management, $v$. 26, n. 2, p. 13-23, 2002.

WEEVERS, Tristan. Web application for UCD Method Selection, 2012. Disponível em: http://ucdtoolbox.com/browse-methods/. Accesso em 22 set. 2018.

ZENG, Liang; PROCTOR, Robert W.; SALVENDY, Gavriel. Creativity in Ergonomic Design: A Supplemental Value-Adding Source for Product and Service Development, Human Factors, v. 52, n. 4, p. 503-525, 2010. 